\title{
REFLEXIONES SOBRE EL TURISMO EN EL ÁMBITO ACADÉMICO ESPAÑOL
}

Ramón Cardona, José ${ }^{1}$

Escuela de Turismo de Ibiza, Universitat de les Illes Balears

jramon.cardona@terra.com

Material original autorizado para su primera publicación en la revista académica REDMARKA. Revista Digital de Marketing Aplicado.

https://doi.org/10.17979/redma.2017.01.018.4859

Recibido: 13 Enero 2017

Aceptado: 15 Mayo 2017

\section{RESUMEN}

España es el tercer país del mundo en llegada de turistas y el segundo en ingresos, siendo en 2015 líder mundial en competitividad turística. El objetivo de este trabajo es revisar bases de datos, realizar comparaciones y determinar posibles líderes en diversos parámetros, con la finalidad de reflexionar sobre la situación del turismo en el ámbito académico español y proponer mejoras. En lo referente a producción científica, las revistas de turismo españolas aun no están evaluadas en el JCR y sólo Cuadernos de Turismo está presente en Scopus. Al analizar las revistas de turismo indexadas en Scopus se observa que la

\footnotetext{
${ }^{1}$ Licenciado en Administración y Dirección de Empresas, Licenciado en Economía y Doctor en Economía de la Empresa por la Universitat de les Illes Balears. Profesor interino de Gestión Turística en la Escuela Universitaria de Turismo del Consell de lbiza (centro adscrito a la Universidad de las Islas Baleares). Colaborador del Grupo de Investigación en Dirección y Gestión de Empresas y Destinos Turísticos.
} 


\section{REFLEXIONES SOBRE EL TURISMO EN EL ÁMBITO ACADÉMICO ESPAÑOL}

Ramón Cardona, José

universidad española con más publicaciones, Universidad de las Islas Baleares (94 artículos en el periodo 2006-2015), está muy alejada de Hong Kong Polytechnic University (907 artículos en el periodo 2006-2015), líder mundial en publicaciones. La situación de España en el ámbito académico no es tan buena como en el ámbito económico. Como medidas de mejora se propone: crear un área oficial de "Turismo y Hospitalidad"; recuperar el catálogo oficial de titulaciones; planificar los centros y plazas docentes; potenciar las revistas españolas; fomentar la creación de departamentos o institutos de investigación, y potenciar la publicación de trabajos innovadores en las revistas de turismo.

Palabras Clave: Turismo, Comparativa, Investigación.

\section{ABSTRACT}

\section{REFLECTIONS ON TOURISM IN THE SPANISH ACADEMIC FIELD}

Spain is the third country of the world in arrival of tourists and the second in income, being in 2015 world leader in tourist competitiveness. The objective of this paper is to review databases, make comparisons and determine potential leaders in various parameters, in order to reflect on the tourism situation in the Spanish academic field and suggest improvements. In terms of scientific production, the Spanish tourism journals are not yet evaluated in the JCR and only Cuadernos de Turismo is present in Scopus. When analyzing the journals indexed in Scopus, it can be observed that the Spanish university with more publications, University of the Balearic Islands (94 articles in the period 20062015), is very far from Hong Kong Polytechnic University (907 articles in the period 2006 -2015), the world leader in publications. The situation of Spain in the academic field is not as good as in the economic sphere. As improvement measures it is proposed: create an official area of "Tourism and Hospitality"; retrieve the official catalog of degrees; planning centers and academic places; promoting the Spanish journals; encourage the creation of departments or 
REFLEXIONES SOBRE EL TURISMO EN EL ÁMBITO ACADÉMICO ESPAÑOL

Ramón Cardona, José

research institutes, and promote the publication of innovative works in tourism journals.

Key Words: Tourism, Comparative, Research. 


\section{REFLEXIONES SOBRE EL TURISMO EN EL ÁMBITO ACADÉMICO ESPAÑOL}

Ramón Cardona, José

\section{INTRODUCCIÓN}

Desde mediados del siglo XX, el sector turístico es fundamental para España, representando una parte muy importante de la actividad económica del país y de la entrada de divisas (INE). Además ha sido el motor de la recuperación económica nacional tras cada crisis económica acaecida en los últimos cincuenta años. El turismo predominante en España es el de sol y playa de origen europeo, pero también existen contingentes de turismo cultural y de compras.

En 2015, hubo 1.186 millones de turistas internacionales en el mundo que generaron unos ingreso de 1.260 .100 millones de dólares y la principal región receptora fue Europa con 607 millones de turistas y unos ingresos de 450.731 millones de dólares (UNWTO, 2016). Ese año, España recibió 68.215.225 turistas extranjeros, principalmente procedentes del Reino Unido (15.724.449), Francia (11.552.680) y Alemania (10.293.964), siendo un impacto importante para los 46.524 .943 de habitantes (INE). Estos 68 millones de turistas dejaron en España unos ingreso de 56.526 millones de dólares. Ello implica que España acaparó el $11,2 \%$ de los turistas y el $12,5 \%$ de los ingresos por turismo internacional en Europa, y el 5,8\% de los turistas y el 4,5\% de los ingresos por turismo internacional en el mundo (UNWTO, 2016).

España es el tercer país del mundo en llegada de turistas internacionales, por detrás de Francia y Estados Unidos, el segundo por ingresos, por detrás de Estados Unidos (UNWTO, 2016), y líder mundial en competitividad turística (Gago \& García, 2016). Además, la única agencia de la ONU con sede en España es la Organización Mundial del Turismo, creada en 1975 y con sede en Madrid. Finalmente hay que indicar que en el sector privado destacan multinacionales como Meliá Hotels International, NH Hotel Group, Riu Hotels \& Resorts, Barceló Hotels \& Resorts, Iberostar Hotels \& Resorts, etc. En base a estos datos, resultaría esperable que la relevancia mundial del sector turístico español fuera acompañada por una relevancia mundial equivalente en el ámbito 


\section{REFLEXIONES SOBRE EL TURISMO EN EL ÁMBITO ACADÉMICO ESPAÑOL}

Ramón Cardona, José

académico. Es decir, que la importancia del turismo fuera respaldada y acompañada por una investigación científica desde el mundo académico igualmente relevante.

El objetivo de este trabajo es revisar bases de datos nacionales e internacionales, realizar comparaciones y determinar posibles líderes en diversos parámetros con la finalidad de reflexionar sobre la situación del turismo en el ámbito académico español. La principal conclusión es que el mundo académico no se encuentra en un nivel mundial equiparable a la importancia económica del sector, principalmente por la falta de acciones que permitirían que el turismo dejara de ser un campo académico de segunda en España.

\section{REVISIÓN DE LA LITERATURA}

Durante décadas, e incluso siglos, la actividad académica tenía pequeñas dimensiones y para los investigadores era fácil conocer los investigadores, centros y publicaciones de su campo. Pero desde la Segunda Guerra Mundial el crecimiento del mundo académico ha sido exponencial, primero por el desarrollo de los países occidentales y más recientemente por el desarrollo de las economías emergentes. El gran tamaño alcanzado a obligado a la aparición de análisis de referencia (Jamal, Smith \& Watson, 2008; McKercher, 2005; Ryan, 2005): "Whitelists" de revistas académicas (ej. Cabell's); bases de dados de publicaciones (Web of Science, Scopus, Dialnet, etc.); catálogos de expertos; rankings de universidades (Academic Ranking of World Universities, QS World University Ranking, etc.), y un largo etcétera.

La investigación académica en turismo es relativamente tardía pero su rápido crecimiento en las últimas décadas (Park, Phillips, Canter \& Abbott, 2011; Vargas, 2011a) ha obligado a realizar diversos tipos de análisis. Frecuentemente, la literatura ha buscado determinar cuáles eran las revistas más importantes en turismo (Ballantyne, Packer \& Axelsen, 2009; Chang \& McAleer, 2012; Ferreira, DeFranco \& Rappole, 1994; Frechtling, 2004; Hall, 


\section{REFLEXIONES SOBRE EL TURISMO EN EL ÁMBITO ACADÉMICO ESPAÑOL}

Ramón Cardona, José

2011; Kim, Savage, Howey \& Van Hoof, 2009; McKercher, Law \& Lam, 2006; Pechlaner, Zehrer, Matzler \& Abfalter, 2004; Ryan, 2005; Svensson, Svaeri \& Einarsen, 2009; Zhao \& Ritchie, 2007), y las tres revistas consideradas tradicionalmente como las más relevantes en turismo son Annals of Tourism Research, Journal of Travel Research, Tourism Management (Li \& Xu, 2015; McKercher, Law \& Lam, 2006; Pechlaner, Zehrer, Matzler \& Abfalter, 2004; Ryan, 2005; Sheldon, 1991). De las tres, Annals of Tourism Research es la más valorada por los académicos (Hall, 2011) y Tourism Management la que posee mejores indicadores bibliométricos (Chang \& McAleer, 2012).

En otros casos se han analizado los autores (Jogaratnam, Chon, McCleary, Mena \& Yoo, 2005; McKercher, 2008; Park, Phillips, Canter \& Abbott, 2011; Ryan, 2005; Zhao \& Ritchie, 2007) y las universidades (Jogaratnam, Chon, McCleary, Mena \& Yoo, 2005; Li \& Xu, 2015; Ryan, 2005; Sheldon, 1991) con mayor producción de artículos. En los años ochenta lideraba en publicaciones la University of Hawaii seguida de la University of Waterloo en Canadá (Sheldon, 1991), en los noventa el liderazgo es de la Texas A\&M University seguida por la Hong Kong Polytechnic University (Jogaratnam, Chon, McCleary, Mena \& Yoo, 2005) y en el nuevo siglo la Hong Kong Polytechnic University lidera a mucha distancia del resto de centros en publicaciones (Li \& Xu, 2015; Severt, Tesone, Bottorff \& Carpenter, 2009) y en editores y miembros del consejo editor de revistas académicas (Law, Leung \& Buhalis, 2010).

En el caso de España han existido revisiones sobre la situación en la que se encontraba la investigación turística desde 1996 en adelante (Aguiló \& Vich, 1996; Antón, López, Marchena \& Vera, 1996; Bigné, 1996; Bote, 1996; Bueno, 1996; Esteban \& Reinares, 1996; Esteban, 2000; Vera \& Ivars, 2001), pero puede destacarse un estudio que analiza las publicaciones durante el periodo 20062011 en 31 revistas de turismo y que engloba diversos países de Iberoamérica (Picazo \& Moreno, 2013b), con especial atención en España (Moreno \& Picazo, 


\section{REFLEXIONES SOBRE EL TURISMO EN EL ÁMBITO ACADÉMICO ESPAÑOL}

Ramón Cardona, José

2012), Brasil (Picazo, Moreno \& León, 2012), Argentina (Picazo \& Moreno, 2012), México (Picazo \& Moreno, 2013a) y Chile (Picazo \& Moreno, 2012).

En diversas ocasiones se ha analizado la contribución de los investigadores españoles en las principales revistas internacionales de turismo (Albacete \& Fuentes, 2010; Moreno \& Picazo, 2012; Vargas, 2011b), habiendo bastante consenso en colocar en los primeros puestos a la Universidad de las Islas Baleares seguida a cierta distancia por las universidades de Las Palmas de Gran Canaria, Alicante, Valencia, Málaga, Jaime I de Castellón, Girona y La Laguna (Albacete \& Fuentes, 2010; Moreno \& Picazo, 2012; Park, Phillips, Canter \& Abbott, 2011). Pero en algunos análisis internacionales basados en un número limitado de revistas académicas de referencia, la Universidad de las Islas Baleares es superada por otras universidades como la Universidad de Las Palmas de Gran Canaria o la Universidad de Alicante (Moreno \& Picazo, 2012; Park, Phillips, Canter \& Abbott, 2011; Severt, Tesone, Bottorff \& Carpenter, 2009).

Aunque la investigación en turismo es transversal a multiples campos de conocimiento académico, el área con más presencia en la investigación turística española es Comercialización e Investigación de Mercados (Albacete \& Fuentes, 2010; Corral, 2013), seguida de cerca por Economía Aplicada gracias al departamento de la Universidad de las Islas Baleares (Albacete \& Fuentes, 2010).

\section{METODOLOGÍA}

El estudio realizado posee semejanzas con trabajos previos (Cheng, Li, Petrick \& O'Leary, 2011; Vargas, 2011b) y busca realizar una revisión de la situación tanto en el ámbito internacional como en el ámbito nacional, en base a información recopilada de diversas fuentes de datos nacionales e internacionales. Las principales fuentes internacionales consultadas han sido: la Master Journal List gestionada por Thomson Reuters y que permite conocer que 


\section{REFLEXIONES SOBRE EL TURISMO EN EL ÁMBITO ACADÉMICO ESPAÑOL}

Ramón Cardona, José

revistas académicas están incluidas en Web of Science, especialmente en el Social Sciences Citation Index (SSCl) y el Emerging Sources Citation Index (ESCI) de reciente creación; la base Scopus posee una mayor cobertura de revistas académicas que Web of Science y resulta de gran utilidad para la búsqueda de bibliografía en áreas de ciencias sociales; el Sistema Regional de Información en Línea para Revistas Científicas de América Latina, el Caribe, España y Portugal (Latindex) para las revistas iberoaméricanas que no estan cubiertas por Web of Science y Scopus; Google Académico para otras busquedas de documentos e investigadores. Las bases de datos nacionales consultadas han sido: las estadísticas del Ministerio de Educación, Cultura y Deportes sobre número de alumnos y tesis defendidas; el Registro de Universidades, Centros y Títulos (RUCT) para la información sobre titulaciones oficiales en España; para los datos más genéricos el Instituto Nacional de Estadística (INE). Al analizar las publicaciones sólo se han tenido en cuenta los artículos, revisiones o notas de investigación publicadas en revistas especializadas en turismo $\mathrm{y} / \mathrm{o}$ hospitalidad.

Estas bases de datos han sido completadas con la búsqueda en diversas páginas de Internet (asociaciones, universidades, etc.) para completar la información y, sobretodo, poder realizar una mejor interpretación de la misma: Universidad de las Islas Baleares, Universidad de Girona, School of Hotel and Tourism Management (Hong Kong Polytechnic University), etc. El análisis realizado en todos los casos es de tipo descriptivo, basado en los datos recopilados en las bases de datos y posteriormente revisado para constrastar su fiabilidad.

Los resultados obtenidos se han estructurado en: un análisis de las revistas existentes y su indexación internacional (Web of Science y Scopus), teniendo en cuenta los criterios normalmente exigidos a los autores para acreditaciones, evaluaciones y solicitud de proyectos; una revisión de los títulos universitarios existentes en España, grados, másteres y doctorados existentes en el Registro 
REFLEXIONES SOBRE EL TURISMO EN EL ÁMBITO ACADÉMICO ESPAÑOL

Ramón Cardona, José

de Universidades, Centros y Títulos (RUCT); exposición de ejemplos especialmente relevantes por sus cifras, tanto en universidades (Hong Kong Polytechnic University) como en investigadores (Rob Law).

\section{LA INVESTIGACIÓN EN TURISMO Y HOSPITALIDAD}

La primera cuestión que se plantea un investigador al incorporarse a un campo académico es donde publicar. Durante los últimos siglos, las revistas académicas han alcanzado gran importancia como medio de difusión y son un reflejo bastante aproximado de la producción científica. Por tanto, conocer la evolución del número de revistas especializadas puede aportar una visión de la evolución de un campo científico. Para este estudio se ha recopilado información sobre revistas especializadas a partir de diversas webs, artículos académicos (Ballantyne, Packer \& Axelsen, 2009; Chang \& McAleer, 2012; Hall, 2011; Svensson, Svaeri \& Einarsen, 2009; Zhao \& Ritchie, 2007) y el uso de buscadores de Internet. En base a ello fue posible elaborar un listado de más de trescientas revistas dedicadas al turismo, la hospitalidad y el ocio. Algunas de estas revistas ya han dejado de publicarse, otras aún no tienen todos los datos recopilados y varias fueron descartadas por tratarse de revistas fraudulentas. Con los datos confirmados fue posible determinar que en 2014 había al menos 211 revistas académicas fiables y activas en el campo del turismo y la hospitalidad (Figura 1).

Figura 1: Revistas académicas activas y confirmadas. 


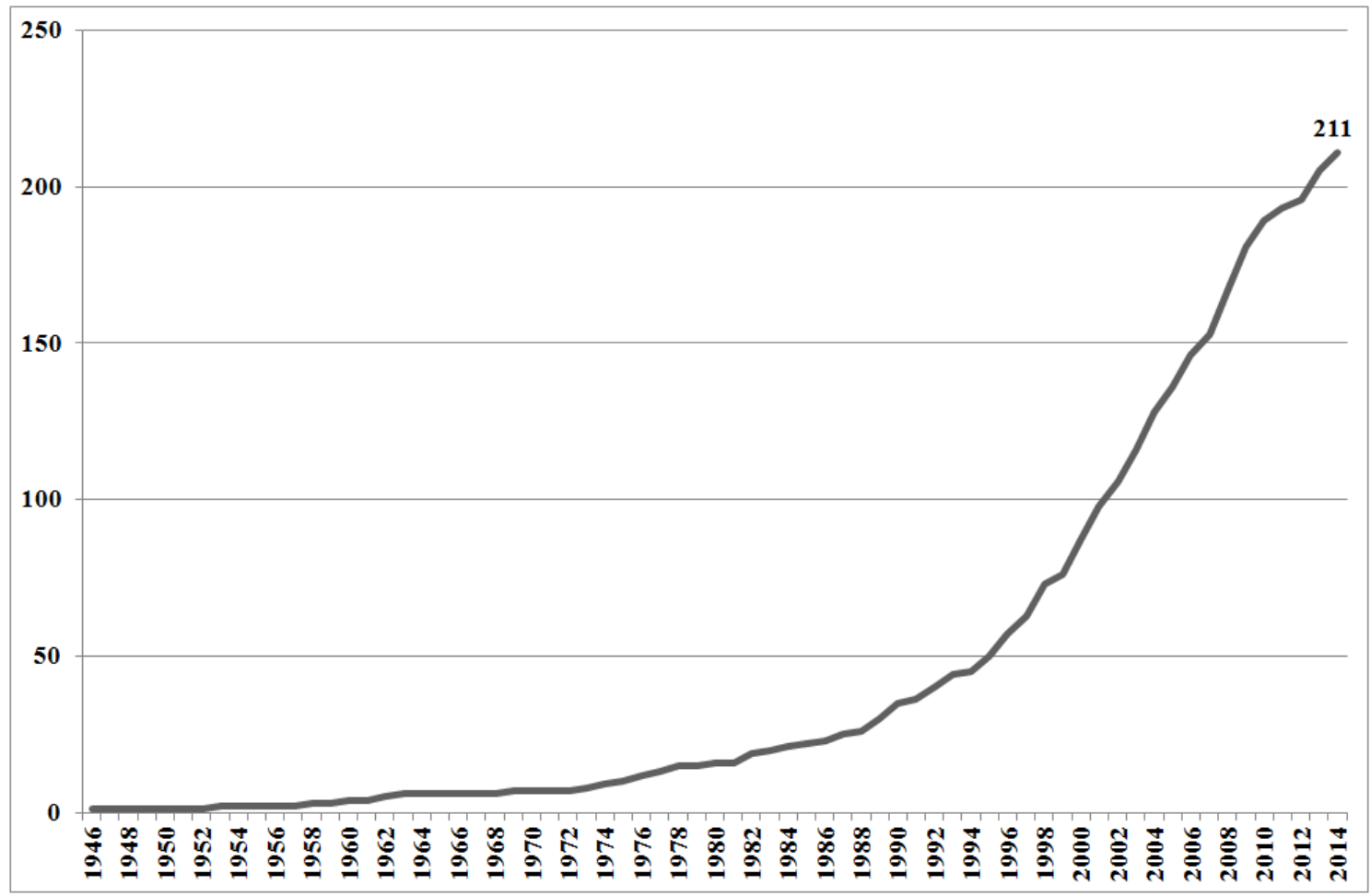

Fuente: elaboración propia.

La primera revista académica de turismo fue The Tourist Review en 1946 y publicaba artículos en diversos idiomas. En la actualidad se sigue publicando, pero sólo en inglés, bajo el nombre de Tourism Review y amparada por la editorial Emerald. En 1963 apareció Estudios Turísticos, revista española pionera en el campo del turismo en lberoamérica. Hasta 1970 aparecieron algunas otras revistas pero de forma muy esporádica. A principios de los años setenta existían siete revistas académicas en el campo del ocio y el turismo, pero aumentó el ritmo de aparición de nuevas revistas. En los años setenta aparecieron una media de 0,9 revistas por año y hay que destacar la aparición de Annals of Tourism Research en 1973. Los inicios de la década de los ochenta destacan por la aparición de International Journal of Tourism Management en 1980, redenominada como Tourism Management en 1982, e International Journal of Hospitality Management en 1982. En los años ochenta aparecieron 


\section{REFLEXIONES SOBRE EL TURISMO EN EL ÁMBITO ACADÉMICO ESPAÑOL}

Ramón Cardona, José

una media de 1,9 revistas académicas y en 1990 ya existían 36 publicaciones académicas en el campo del turismo.

Puede hablarse de una "Era de los Pioneros" en la investigación turística al referirse a la situación anterior a 1990: pocos investigadores, pocas revistas académicas y mala imagen de este campo de estudio. Los investigadores que iniciaron su actividad en los años setenta y ochenta constituyen la primera generación de investigadores en turismo y, en muchos casos, fueron los impulsores de los primeros grupos y departamentos que surgieron en diversas partes del mundo. Hay bastantes similitudes entre estos pioneros, independientemente de su área académica (economía, geografía, sociología, antropología, etc.), en la reacción que sufrieron de sus colegas cuando decidieron llevar su área de investigación al campo del turismo. Muchos investigadores no consideraban ciencia seria las investigaciones turísticas, aunque usaran las mismas metodologías y criterios de rigor que el resto de investigaciones.

En los años noventa aparecieron una media de 5,2 revistas y en el año 2000 había 88 revistas académicas. En esta época apareció la primera oleada de revistas académicas de Iberoamérica: Papers de Turisme (1989), Adoz: Revista de Estudios de Ocio (1994), Cuadernos de Turismo (1998) y Annals of Tourism Research en Español (1999-2012) en España; Turismo em Análise (1990), Boletim de Turismo e Administração Hoteleira (1992-2002), Reuna (1996), Turismo: Tendências e Debates (1998-2005) y Turismo: Visão e Ação (1998) en Brasil; Estudios y Perspectivas en Turismo (1991) y Aportes y Transferencias (1997-2011) en Argentina; Revista Universitaria de Turismo y Administración (1994) y Gestión Turística (1995) en Chile; Percursos \& Ideias (1998) en Portugal; El Periplo Sustentable (2000) en México; etc. En el caso de España fue de gran relevancia la incorporación de los estudios en turismo a la universidad en 1996, con rango de diplomatura (tres años). 


\section{REFLEXIONES SOBRE EL TURISMO EN EL ÁMBITO ACADÉMICO ESPAÑOL}

Ramón Cardona, José

Con el inicio del nuevo siglo se produjo una aceleración en el crecimiento de la investigación en turismo, tanto a nivel mundial (Park, Phillips, Canter \& Abbott, 2011) como nacional (Vargas, 2011a). Durante la primera década del nuevo siglo apareció una media de más de doce revistas académicas al año, tendencia que más o menos se ha mantenido desde entonces. El riesgo de una expansión tan rápida es el surgimiento de revistas fraudulentas que buscan obtener ingresos a costa de la desesperación o ignorancia de los investigadores jóvenes o de países emergentes. Ello ha obligado a la aparición de Blacklists, como la creada por Jeffrey Beall (University of Colorado Denver), y plataformas de indexación. En España se han adoptado como plataformas de indexación de referencia Web of Science por ser la más antigua y prestigiosa en las ciencias experimentales, Scopus por su mayor cobertura de revistas académicas, y Latindex por su análisis formal de las revistas iberoamericanas. En otros países han optado por listados propios y oficiales basados en el prestigio de las revistas entre los académicos y que clasifican las publicaciones en cuatro o cinco niveles dentro de cada temática. Estas Whitelists han sido adoptadas por los organismos oficiales de países como Australia, Reino Unido, Italia o Colombia, pero en España no ha sido así a pesar de existir diversas propuestas de este estilo.

Las revistas académicas de turismo indexadas en Web of Science se encuentran integradas en la categoría de Hospitality, Leisure, Sport \& Tourism del SSCI y del ESCI. Esta categoría engloba deportes, ocio, turismo y hospitalidad, con lo cual no todas las revistas que contiene son útiles para los investigadores en turismo. En la actualidad, la categoría de Hospitality, Leisure, Sport \& Tourism en $\mathrm{SSCl}$ contiene 45 publicaciones y en ESCl otras 45 publicaciones.

Social Sciences Citation Index (SSCI) forma parte del listado clásico de Web of Science y por asimilación al Science Citation Index Expanded es objeto de un Journal Citation Report (JCR) que determina los cuartiles en que se divide el listado en base al factor de impacto a dos años. De las 45 publicaciones de la categoría Hospitality, Leisure, Sport \& Tourism sólo 20 son sobre turismo o 
REFLEXIONES SOBRE EL TURISMO EN EL ÁMBITO ACADÉMICO ESPAÑOL

Ramón Cardona, José

hospitalidad. Dos o tres más son sobre ocio y el resto están dedicadas a la investigación en deportes, otra área con pocas publicaciones indexadas. Además, las publicaciones de turismo han entrado en este índice de forma muy reciente y hasta 2006 sólo dos publicaciones de turismo eran cubiertas por Web of Science: Annals of Tourism Research y Tourism Management. La mayor parte de las incorporaciones se produjeron en 2008 y 2009 y la última es de 2015 (Figura 2).

Figura 2: Evolución de las revistas de turismo indexadas en SSCl.

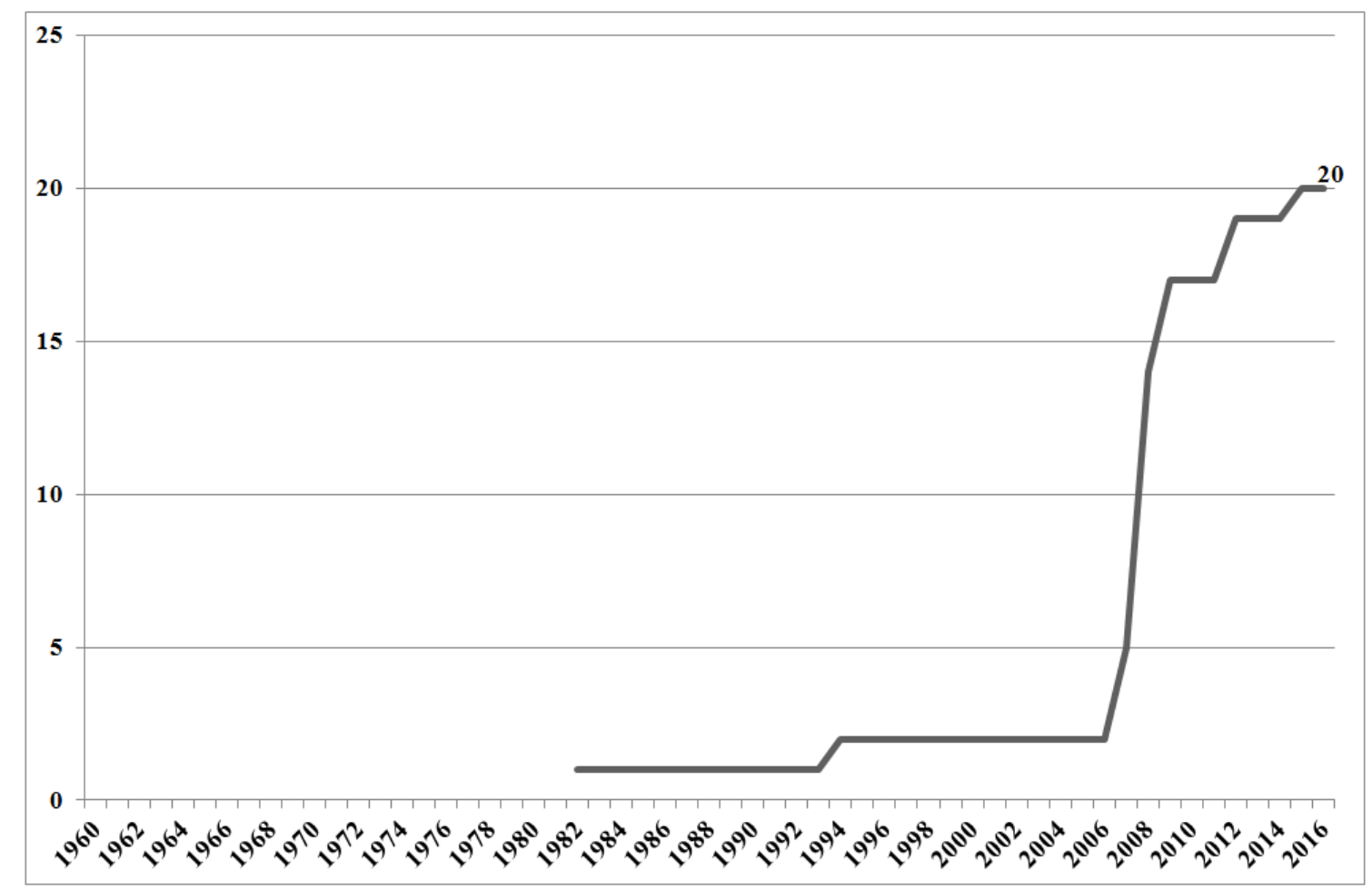

Fuente: Master Journal List y elaboración propia.

Emerging Sources Citation Index (ESCl) es un listado de reciente creación (noviembre de 2015) que engloba publicaciones en proceso de evaluación para su entrada en $\mathrm{SSCl}$, pero ya han superado una primera criba (Master Journal List). En septiembre de 2016 la categoría Hospitality, Leisure, Sport \& Tourism contenía 45 revistas, 28 de ellas sobre turismo. Una de las revistas de turismo 
REFLEXIONES SOBRE EL TURISMO EN EL ÁMBITO ACADÉMICO ESPAÑOL

Ramón Cardona, José

indexadas en $\mathrm{ESCl}$ ya ha superado el proceso de evaluación y ha pasado a SSCl: Journal of Vacation Marketing. No está claro que pasara con las revistas que finalmente no completen el proceso de evaluación satisfactoriamente.

Scopus es la base de indexación más grande y es un elemento complementario de Web of Science en los proceso de evaluación. En la categoría de Tourism, Leisure and Hospitality Management están englobadas 71 revistas que publican sobre turismo, ocio y hospitalidad, aunque algunas no están especializadas. 61 de estas revistas están especializadas en turismo y hospitalidad, siendo las otras 10 de ocio o generalistas. Dentro de estas 61 revistas quedan incluidas las 20 revistas integradas en el SSCI. En este caso también se ha producido un aumento muy reciente en el volumen de publicaciones indexadas (Figura 3).

Figura 3. Evolución de las revistas de turismo indexadas en Scopus.

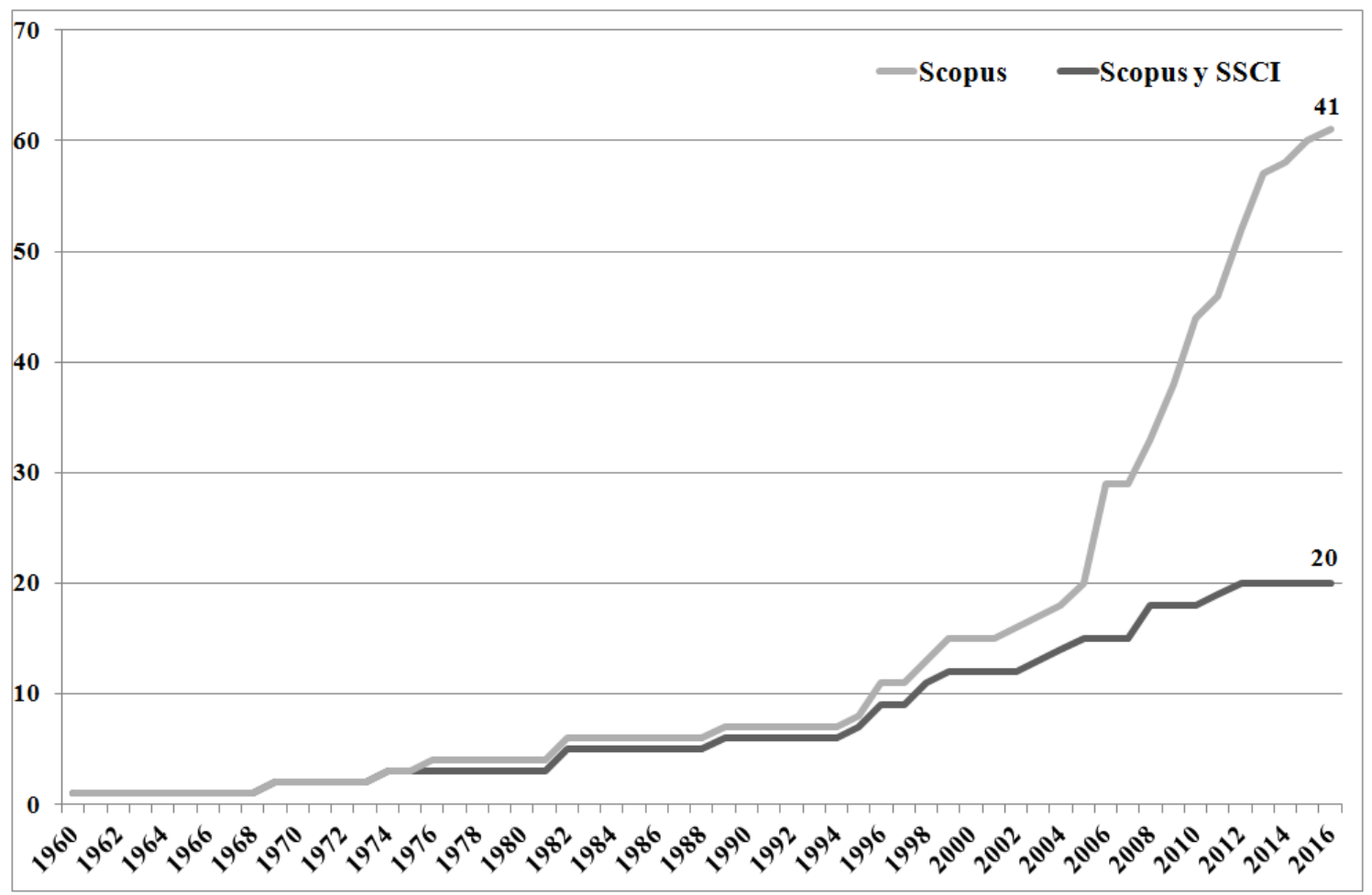

Fuente: Scopus y elaboración propia. 


\section{REFLEXIONES SOBRE EL TURISMO EN EL ÁMBITO ACADÉMICO ESPAÑOL}

Ramón Cardona, José

Finalmente, como tercera opción de evaluación de revistas está Latindex. En este caso es un catalogo de revistas iberoamericanas que son evaluadas en base a 33 criterios las revistas en papel y 36 criterios las revistas on-line, siendo necesario cumplir al menos 25 criterios incluyendo los primeros ocho del listado para pasar del directorio al catálogo. A septiembre de 2016, había 43 revistas activas y especializadas en turismo incluidas en el catálogo.

Las revistas de turismo españolas aun no están indexadas en el SSCl y sólo Cuadernos de Turismo está indexada en Scopus. Si existen posibilidades de mejora en esta indexación por el hecho de que diversas revistas están en el ESCI de Web of Science y, por tanto, están trabajando para entrar en el SSCI: Cuadernos de Turismo; Investigaciones Turísticas; PASOS: Revista de Turismo y Patrimonio Cultural. En el catalogo Latindex aparecen 10 revistas académicas españolas: Cuadernos de Turismo; Enlightening Tourism: A Pathmaking Journal; Gran Tour; International Journal of Scientific Management and Tourism; Investigaciones Turísticas; Papers de Turisme; PASOS: Revista de Turismo y Patrimonio Cultural; Revista de Análisis Turístico; ROTUR: Revista de Ocio y Turismo; TURyDES: Revista de Investigación en Turismo y Desarrollo Local. Ello implica que las revistas españolas son poco valoradas en las evaluaciones nacionales.

En lo referente a la formación académica, cabe indicar que los estudios en turismo no fueron incorporados oficialmente a la universidad española hasta 1996 (R.D. 259/1996). Antes existió durante más de treinta años un título técnico profesional de Técnico de Empresas Turísticas (1963-1980) o Técnico en Empresas y Actividades Turísticas (1980-1996) respaldado por el ministerio competente en turismo y expedido por la Escuela Oficial de Turismo (creada en 1963), aunque había docenas de escuelas de turismo por toda España que preparaban para los exámenes oficiales de obtención del título (Ceballos, Arias, Ruiz, Sanz, \& Vázquez, 2009). Finalmente, a finales de los noventa el turismo entró en las universidades (R.D. 259/1996) como Diplomatura en Turismo (R.D. 


\section{REFLEXIONES SOBRE EL TURISMO EN EL ÁMBITO ACADÉMICO ESPAÑOL}

Ramón Cardona, José

604/1996) y hubo un proceso masivo de adscripción de las escuelas de turismo previamente existentes a las universidades (Abril, 2015; Vera \& Ivars, 2001).

A principios de los noventa aparecieron títulos propios de Grado Superior en Turismo que debían ser un antecedente de una futura Licenciatura en Turismo, y cabe destacar como pionera y por su plan de estudios la Universidad de las Islas Baleares. A principios del siglo XXI existían al menos una docena de grados superiores en distintas universidades españolas pero al plantearse la reforma de las titulaciones universitarias para adaptarlas al Espacio Europeo de Educación Superior (EEES) fueron abandonándose los grados superiores y planteándose los futuros másteres universitarios en turismo. Finalmente, nunca llegó a producirse el reconocimiento oficial de una Licenciatura en Turismo.

Con el EEES se decidió adoptar una estructura de Grado, Máster y Doctorado (R.D. 1393/2007), inspirada en el sistema universitario de Estados Unidos. La estructura de Grado y Máster en 3+2 o 4+1 años no era la más correcta en base al ejemplo de los países anglosajones. En el mundo anglosajón, la experiencia ha demostrado que los grados deben ser de cuatro años y los másteres de mínimo dos, es decir seis años en total y no cinco como se buscaba con el EEES. Además, en España se abandonó el catalogo de titulaciones y materias troncales dejando libertad a los centros a cambio de un control de calidad fundamentado esencialmente en la documentación aportada a la Agencia Nacional de Evaluación de la Calidad y Acreditación (ANECA).

El resultado es que se ha llegado a la situación de que en el curso 2015/2016 había 8.181 titulaciones oficiales en las universidades españolas (2.723 grados, 3.782 másteres, 1.075 doctorados, 571 programas conjuntos de grado y 30 programas conjuntos de máster) según el RUCT, aunque hay que indicar que este registro esta poco actualizado y no es demasiado fiable. De estas titulaciones, al menos 55 grados, 51 másteres y 6 doctorados hacían referencia al turismo y la gestión turística, no existiendo estadísticas oficiales sobre número de titulaciones o alumnos en este campo. Este caos de titulaciones, debido en 


\section{REFLEXIONES SOBRE EL TURISMO EN EL ÁMBITO ACADÉMICO ESPAÑOL}

Ramón Cardona, José

gran parte al abandono del catalogo oficial, ha creado una gran oferta con nombres y contenidos muy variables.

El Grado en Turismo y la previa Diplomatura en Turismo son vistos en muchos casos como una titulación inferior a Economía o Administración de Empresas (Abril, 2015; Guevara \& Caro, 2006). En otros casos la falta de profesorado con perfil claramente de turismo ha hecho que estos estudios sean considerados "empresariales con idiomas". Los centros adscritos, creados en muchas ocasiones como un negocio que aprovechaba el tirón del boom turístico, tienen un funcionamiento demasiado parecido a un centro de formación profesional y es posible que el futuro de la mayoría de ellos sea la desaparición.

Finalmente indicar que no hubo una equiparación de las diplomaturas a los grados y de las licenciaturas a los másteres hasta 2015 (Resolución de 20 de octubre de 2015, publicada el 2 de noviembre, para el caso de la Diplomatura en Turismo) y durante una década fueron necesarios cursos puente para que los estudiantes pudieran pasar de las antiguas titulaciones a las nuevas. En 2016 había 50 universidades que impartían el Grado en Turismo en centros propios o adscritos y cinco que imparten grados en Gestión Turística. En total, 53 universidades españolas imparten grados en turismo y hospitalidad (Tabla 1).

Tabla 1: Universidades con titulaciones en turismo.

\begin{tabular}{|c|c|c|c|}
\hline UNIVERSIDAD & GRADO & MÁSTER & DOCTORADO \\
\hline IE Universidad & 1 & & \\
\hline Universidad a Distancia de Madrid & 1 & 2 & \\
\hline Universidad Alfonso X El Sabio & 1 & & \\
\hline Universidad Antonio de Nebrija & 1 & 1 & \\
\hline Universidad Autónoma de Barcelona & 2 & 2 & \\
\hline Universidad Autónoma de Madrid & 1 & & \\
\hline Universidad Carlos III de Madrid & 1 & 1 & \\
\hline Universidad Católica San Antonio & 1 & 2 & \\
\hline Universidad Complutense de Madrid & 1 & 2 & \\
\hline Universidad de A Coruña & 1 & & \\
\hline Universidad de Alcalá de Henares & 1 & & \\
\hline
\end{tabular}




\section{REFLEXIONES SOBRE EL TURISMO EN EL ÁMBITO ACADÉMICO ESPAÑOL}

Ramón Cardona, José

\begin{tabular}{|c|c|c|c|}
\hline Universidad de Alicante & 1 & 1 & 1 \\
\hline Universidad de Almería & 1 & & \\
\hline Universidad de Barcelona & 1 & 4 & \\
\hline Universidad de Burgos & 1 & 1 & \\
\hline Universidad de Cádiz & 1 & 1 & \\
\hline Universidad de Cantabria & 1 & 2 & \\
\hline Universidad de Córdoba & 1 & & \\
\hline Universidad de Deusto & 1 & 1 & \\
\hline Universidad de Extremadura & 1 & 1 & \\
\hline Universidad de Girona & 2 & 5 & 1 \\
\hline Universidad de Granada & 1 & & \\
\hline Universidad de Huelva & 1 & 1 & \\
\hline Universidad de Jaén & 1 & 2 & \\
\hline Universidad de La Laguna & 1 & 2 & 1 \\
\hline Universidad de La Rioja & 1 & & \\
\hline Universidad de las Islas Baleares & 1 & 3 & 1 \\
\hline Universidad de Las Palmas de Gran Canaria & 1 & 4 & 1 \\
\hline Universidad de León & 1 & & \\
\hline Universidad de Lleida & 1 & & \\
\hline Universidad de Málaga & 1 & 2 & 1 \\
\hline Universidad de Murcia & 1 & 1 & \\
\hline Universidad de Oviedo & 1 & 1 & \\
\hline Universidad de Salamanca & 1 & & \\
\hline Universidad de Santiago de Compostela & & 1 & \\
\hline Universidad de Sevilla & 1 & 1 & 1 \\
\hline Universidad de Valencia & 1 & 1 & 1 \\
\hline Universidad de Valladolid & 1 & & \\
\hline Universidad de Vic & 1 & & \\
\hline Universidad de Vigo & 1 & 1 & \\
\hline Universidad de Zaragoza & 1 & 1 & \\
\hline Universidad del País Vasco & & 1 & \\
\hline Universidad Europea de Canarias & 1 & & \\
\hline Universidad Europea de Madrid & 1 & 1 & \\
\hline Universidad Europea de Valencia & 1 & & \\
\hline Universidad Europea Miguel de Cervantes & 1 & & \\
\hline Universidad Internacional de Andalucía & & 1 & \\
\hline Universidad Jaume I de Castellón & 1 & & \\
\hline Universidad Miguel Hernández de Elche & & 1 & \\
\hline Universidad Nacional de Educación a Distancia & 1 & & \\
\hline Universidad Politécnica de Cartagena & 1 & 1 & \\
\hline Universidad Politécnica de Valencia & 1 & & \\
\hline Universidad Pompeu Fabra & 1 & & \\
\hline Universidad Ramón Llull & 1 & 1 & \\
\hline
\end{tabular}

REDMARKA UIMA-Universidad de A Coruña - CIECID

Año X, Número 18, (2017), v I pp. 83-115

http://www.redmarka.net/ ISSN 1852-2300 


\section{REFLEXIONES SOBRE EL TURISMO EN EL ÁMBITO ACADÉMICO ESPAÑOL}

Ramón Cardona, José

\begin{tabular}{|llll|}
\hline Universidad Rey Juan Carlos & 1 & 1 & 1 \\
\hline Universidad Rovira i Virgili & 1 & 2 & 1 \\
\hline Universitat Oberta de Catalunya & 1 & & \\
\hline
\end{tabular}

Fuente: RUCT y elaboración propia.

En el caso de los títulos de Máster Universitario el caos es mayor. La regulación de los títulos de máster y doctorado fue aprobada antes que la de los grados y ha sido modificada en diversas ocasiones: los títulos de máster en 2005 (R.D. 56/2005) y 2007 (R.D. 1393/2007), y los de doctorado en 2005 (R.D. 56/2005), 2007 (R.D. 1393/2007) y 2011 (R.D. 99/2011). En este caso no es posible achacar este hecho a un cambio de gobierno, ya que de 2004 a 2011 el presidente del Gobierno de España fue José Luís Rodríguez Zapatero. Los másteres tienen perfiles posiblemente mejorables en algunos casos (Agroecología, Desarrollo Rural y Agroturismo; Cultura del Vino: Enoturismo en la Cuenca del Duero; Dirección de Proyectos de Ocio, Cultura, Turismo, Deporte y Recreación; Economía del Turismo y Medio Ambiente; Gestión Estratégica Sostenible de Destinos Turísticos; Innovación en Diseño para el Sector Turístico; Técnicas de Análisis e Innovación Turística; Turismo Urbano y Gestión de Empresas Turísticas; Turismo, Arqueología y Naturaleza; etc.) y dificultades para completar la totalidad de las plazas. Según el Tribunal de Cuentas (2015), en el curso 2012/2013 sólo se cubrió el $61 \%$ de las plazas de máster en las universidades públicas españolas. El principal resultado es la desaparición de muchos de estos títulos después de dos o tres años de impartición, principalmente por falta de alumnos. En el RUCT aparecen 35 universidades con títulos de máster universitario en turismo y hospitalidad (Tabla 1) pero no pueden considerarse actualizados los datos del RUCT en este punto.

En 2014 se defendieron 11.316 tesis doctorales en España (Ministerio de Educación, Cultura y Deportes), entre todas las áreas académicas. Eso representa 6.700 tesis más de las necesarias para mantener en el largo plazo los 210.104 puestos de investigador existentes en España (INE). Ello indica que 


\section{REFLEXIONES SOBRE EL TURISMO EN EL ÁMBITO ACADÉMICO ESPAÑOL}

Ramón Cardona, José

las propuestas para aumentar la producción de tesis doctorales, reduciendo el plazo de elaboración y la extensión de las mismas, no es la decisión correcta, salvo que se pretenda aumentar la sobrecualificación entre las personas con doctorado. En todo caso es necesario potenciar tesis de mayor calidad y dirigir los doctorandos hacia las áreas con mayor potencial de futuro.

Tabla 2: Programas de Doctorado en Turismo en base al R.D. 99/2011.

\begin{tabular}{|ll|}
\hline TíTULo & UNIVERSIDAD \\
\hline Doctorado en Derecho, Sociedad y Turismo & Universidad de La Laguna \\
\hline $\begin{array}{l}\text { Doctorado en Economía Internacional y yniversidad de Valencia } \\
\text { Turismo }\end{array}$ & Universidad de Las Palmas de Gran \\
\hline Doctorado en Turismo, Economía y Gestión & $\begin{array}{l}\text { Univer } \\
\text { Canaria }\end{array}$ \\
\hline Doctorado en Turismo & $\begin{array}{l}\text { Universidad de Alicante } \\
\text { Universidad de Málaga } \\
\text { Universidad de Sevilla } \\
\text { Universidad Rey Juan Carlos }\end{array}$ \\
\hline Doctorado en Turismo & $\begin{array}{l}\text { Universidad de Girona } \\
\text { Universidad de las Islas Baleares }\end{array}$ \\
\hline Doctorado en Turismo y Ocio & Universidad Rovira i Virgili \\
\hline
\end{tabular}

\section{Fuente: RUCT y elaboración propia.}

Aunque existen tesis en turismo desde hace décadas, los programas de doctorado en turismo son bastante recientes. Las diversas normativas y la falta de alumnos han causado la aparición y desaparición de programas de doctorado con gran frecuencia a lo largo de los primeros quince años del siglo XXI. Además, todos los alumnos de programas de doctorado anteriores al R.D. 99/2011 se vieron obligados a defender la tesis o cambiar de programa antes de febrero de 2016, causando que se defendieran enormes volúmenes de tesis doctorales en todas las áreas durante los meses previos a esa fecha. Desgraciadamente existen dudas sobre la calidad de algunas de esas tesis doctorales. Desde esa fecha sólo perviven los doctorados del R.D. 99/2011, seis de ellos enfocados al 
REFLEXIONES SOBRE EL TURISMO EN EL ÁMBITO ACADÉMICO ESPAÑOL

Ramón Cardona, José

turismo (Tabla 2) aunque otros programas engloban el turismo en alguna de sus líneas.

No hay estadísticas oficiales de tesis sobre "Turismo y Hostelería" hasta el año 2013: 25 tesis en 2013 y 22 tesis en 2014 (15 en español, 2 en catalán, 3 en inglés y 2 en portugués). Sólo 14 tesis de 2014 obtuvieron el "cum laude", con lo que ello implica dadas las tradiciones académicas españolas. En 2014/2015 había 131 estudiantes de doctorado en programas de "Viajes, Turismo y Ocio" amparados por el R.D. 99/2011 (21 en la Universidad de Alicante, 34 en la Universidad de Girona, 18 en la Universidad de las Islas Baleares, 23 en la Universidad de Málaga, 11 en la Universidad Rey Juan Carlos, 18 en la Universidad Rovira y Virgili y 6 en la Universidad de Sevilla) de un total de 32.062 estudiantes de doctorado. Aunque parezcan cifras bajas, con este volumen de tesis al año es posible mantener a largo plazo una plantilla de 1.100 investigadores.

Figura 4: Artículos en revistas de turismo Scopus (2006-2015). 


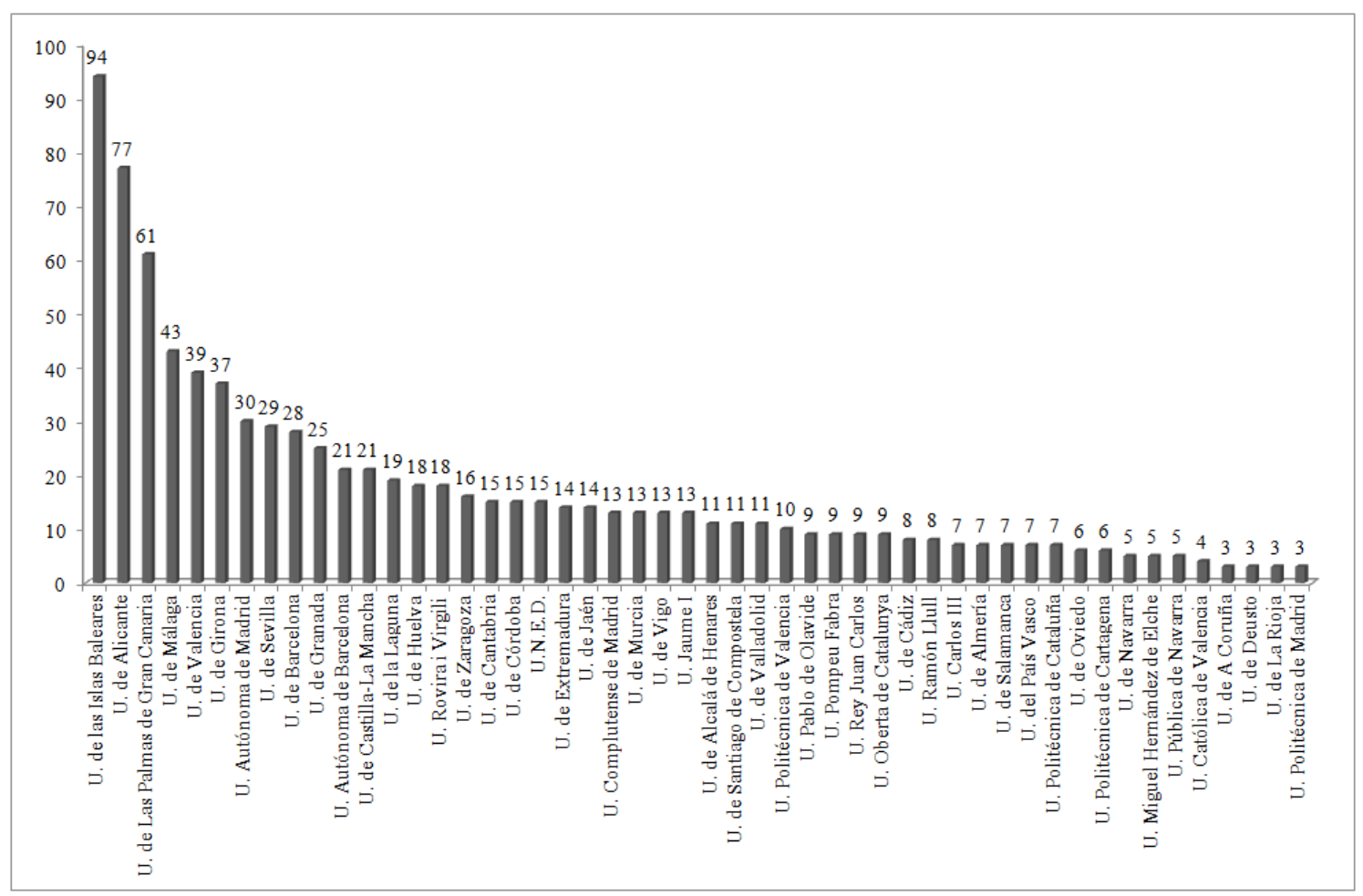

\section{Fuente: Scopus y elaboración propia.}

En base a los datos del RUCT, 22 universidades tienen grado en turismo pero no máster en turismo, siendo poco más que college en terminología norteamericana. De las 35 universidades con máster en turismo sólo 10 están adscritas a uno de los seis programas de doctorado en turismo actualmente vigentes. Por tanto, sólo las 10 universidades españolas con estudios de Grado, Máster y Doctorado en turismo pueden considerarse como candidatas a polo de investigación turística, habiendo gran coincidencia entre este listado y las principales universidades por volumen de publicaciones en el área (Figura 4). El resto de universidades poseen investigadores en turismo dispersos por diversos departamentos pero no muestran una apuesta clara por este campo de investigación.

Al analizar las revistas de turismo indexadas en Scopus se observa que la universidad española con más referencias, la Universidad de las Islas Baleares (94 artículos en el periodo 2006-2015 y 120 en total) está muy alejada de la Hong 


\section{REFLEXIONES SOBRE EL TURISMO EN EL ÁMBITO ACADÉMICO ESPAÑOL}

Ramón Cardona, José

Kong Polytechnic University (907 artículos en el periodo 2006-2015 y 975 en total), líder mundial en publicaciones turísticas en Scopus y en diversos estudios bibliométricos publicados en los últimos años (Li \& Xu, 2015; Severt, Tesone, Bottorff \& Carpenter, 2009).

La Universidad de las Islas Baleares no ha cuidado suficientemente su oferta educativa oficial y no oficial en los últimos años. En la actualidad posee un título de Grado (Turismo), dos de Máster Universitario (Dirección y Planificación del Turismo; Economía del Turismo: Monitorización y Evaluación) y uno de doctorado (Doctorado en Turismo). El Grado en Turismo queda eclipsado por los otros 54 títulos universitarios existentes en España. Los dos másteres son de creación muy reciente (año 2015), uno de ellos es conjunto con una escuela de turismo de la Universidad Pompeu Fabra (Dirección y Planificación del Turismo) y no existe un máster de investigación en turismo. El doctorado existente es conjunto con la Universidad de Girona, que lo coordina, tiene pocos alumnos en la actualidad y no hay constancia de Mencionas hacia la Excelencia. El Doctorado en Economía Aplicada tiene una línea en Economía del Turismo y si ha recibido alguna Mención hacia la Excelencia. Esta oferta se ve complementada con tres títulos propios con gran tradición en dos de los casos: Diploma Universitario de Dirección Hotelera Internacional, Máster en Gestión Turística y Máster en Contratación Turística. Más interesante resulta la oferta de la Universidad de Girona: dos Grados (Turismo; Gestión Hotelera y Turística), tres títulos de Máster Universitario (Dirección y Planificación del Turismo; Turismo Cultural; Erasmus Mundus en Gestión del Turismo), un programa de doctorado (Doctorado en Turismo) y tres títulos propios (Máster en Dirección y Gestión de Alojamientos Turísticos; Máster en Dirección y Gestión de Hoteles y Restaurantes; Máster en E-Commerce y Marketing Turístico).

En referencia al volumen de publicaciones, la Universidad de las Islas Baleares ha perdido ventaja respecto al resto de universidades españolas (Moreno \& Picazo, 2012; Park, Phillips, Canter \& Abbott, 2011; Severt, Tesone, Bottorff \& 


\section{REFLEXIONES SOBRE EL TURISMO EN EL ÁMBITO ACADÉMICO ESPAÑOL}

Ramón Cardona, José

Carpenter, 2009) y sus publicaciones en Scopus se deben en gran parte a varios grupos del departamento de Economía Aplicada y a artículos en la revista Tourism Economics (cerca de 50). Resulta cuanto menos llamativo que la universidad que lideraba las iniciativas en este campo en los noventa hoy sea una más entre las primeras. Posiblemente este hecho se deba a decisiones de gestión interna que han limitado su potencial en el campo del turismo y la hospitalidad: atomización de la investigación en múltiples grupos, departamentos y áreas; potenciación de áreas más "clásicas", etc.

\section{Tabla 3: Titulaciones de la School of Hotel and Tourism Management.}

\begin{tabular}{|ll|}
\hline TITULO & EsPECIALIDAD \\
\hline Bachelor of Science (B.Sc.) (Hons) & Convention and Event Management \\
& Hotel Management \\
& Tourism Management \\
& Hotel and Tourism Management \\
\hline Master of Science (M.Sc.) & Global Hospitality Business \\
& International Hospitality Management \\
& International Wine Management \\
& International Tourism and Convention \\
& Management \\
& Hotel and Tourism Management \\
\hline Higher Diploma (H.D.) & Hotel Management \\
\hline Doctor of Hotel and Tourism Management (D.HTM) \\
\hline Doctor of Philosophy (Ph.D.) & Hotel and Tourism Management \\
\hline
\end{tabular}

Fuente: School of Hotel and Tourism Management y elaboración propia.

Por contra, Hong Kong Polytechnic University concentra la docencia e investigación turística en la School of Hotel and Tourism Management, posee una amplia oferta de titulaciones en turismo (Tabla 3) e investigadores con elevados niveles de producción científica: Bob McKercher, Haiyan Song, Cathy H. C. Hsu, Karin Weber, Wilco W. Chan, Hanqin Zhang Qiu, Catherine Cheung, Henry Tsai, entre otros (Park, Phillips, Canter \& Abbott, 2011; Scopus). También 


\section{REFLEXIONES SOBRE EL TURISMO EN EL ÁMBITO ACADÉMICO ESPAÑOL}

Ramón Cardona, José

debe destacarse la enorme presencia de sus profesores en los consejos editores de múltiples revistas académicas de turismo y hospitalidad (Law, Leung \& Buhalis, 2010).

Tabla 4: Artículos de Rob Law en Scopus a 15 de septiembre de 2016.

\begin{tabular}{|c|c|c|c|}
\hline REVISTA & SSCI & Scopus & TOTAL \\
\hline Anatolia & & 1 & 1 \\
\hline Annals of Tourism Research & 7 & & 7 \\
\hline Asia Pacific Journal of Tourism Research & 19 & 7 & 26 \\
\hline Cornell Hospitality Quarterly & 8 & 1 & 9 \\
\hline Current Issues in Tourism & 3 & & 3 \\
\hline International Journal of Contemporary Hospitality Management & 13 & 7 & 20 \\
\hline International Journal of Hospitality and Tourism Administration & & 4 & 4 \\
\hline International Journal of Hospitality Management & 22 & 7 & 29 \\
\hline International Journal of Tourism Research & 5 & & 5 \\
\hline Journal of China Tourism Research & & 3 & 3 \\
\hline Journal of Destination Marketing and Management & & 1 & 1 \\
\hline Journal of Hospitality and Tourism Education & & 1 & 1 \\
\hline Journal of Hospitality and Tourism Management & & 6 & 6 \\
\hline Journal of Hospitality and Tourism Research & 6 & 6 & 12 \\
\hline Journal of Hospitality Marketing and Management & & 6 & 6 \\
\hline Journal of Hospitality, Leisure, Sports and Tourism Education & 2 & & 2 \\
\hline Journal of Human Resources in Hospitality and Tourism & & 1 & 1 \\
\hline Journal of Quality Assurance in Hospitality and Tourism & & 3 & 3 \\
\hline Journal of Sustainable Tourism & 2 & 1 & 3 \\
\hline Journal of Teaching in Travel and Tourism & & 3 & 3 \\
\hline Journal of Travel and Tourism Marketing & 38 & & 38 \\
\hline Journal of Travel Research & 6 & 1 & 7 \\
\hline Journal of Vacation Marketing & 1 & & 1 \\
\hline Tourism Analysis & & 1 & 1 \\
\hline Tourism Management & 26 & & 26 \\
\hline Tourism Management Perspectives & & 1 & 1 \\
\hline TOTAL & 158 & 61 & 219 \\
\hline
\end{tabular}

Fuente: Scopus y elaboración propia.

A nivel individual, los investigadores españoles están lejos de las cifras de algunos investigadores extranjeros. En base a la consulta de las revistas 
indexadas en Scopus, el autor con más artículos es Rob Law, Professor of Hotel and Tourism Technology Management en la School of Hotel and Tourism Management (Hong Kong Polytechnic University, Hong Kong). Tiene 318 documentos en Scopus a 15 de septiembre de 2016 pero muchos son editoriales o reseñas. De ellos, 219 son artículos publicados en revistas de turismo y hospitalidad (Tabla 4) en un periodo de menos de 20 años (Figura 5).

Figura 5. Artículos en revistas de turismo de Scopus (Rob Law).

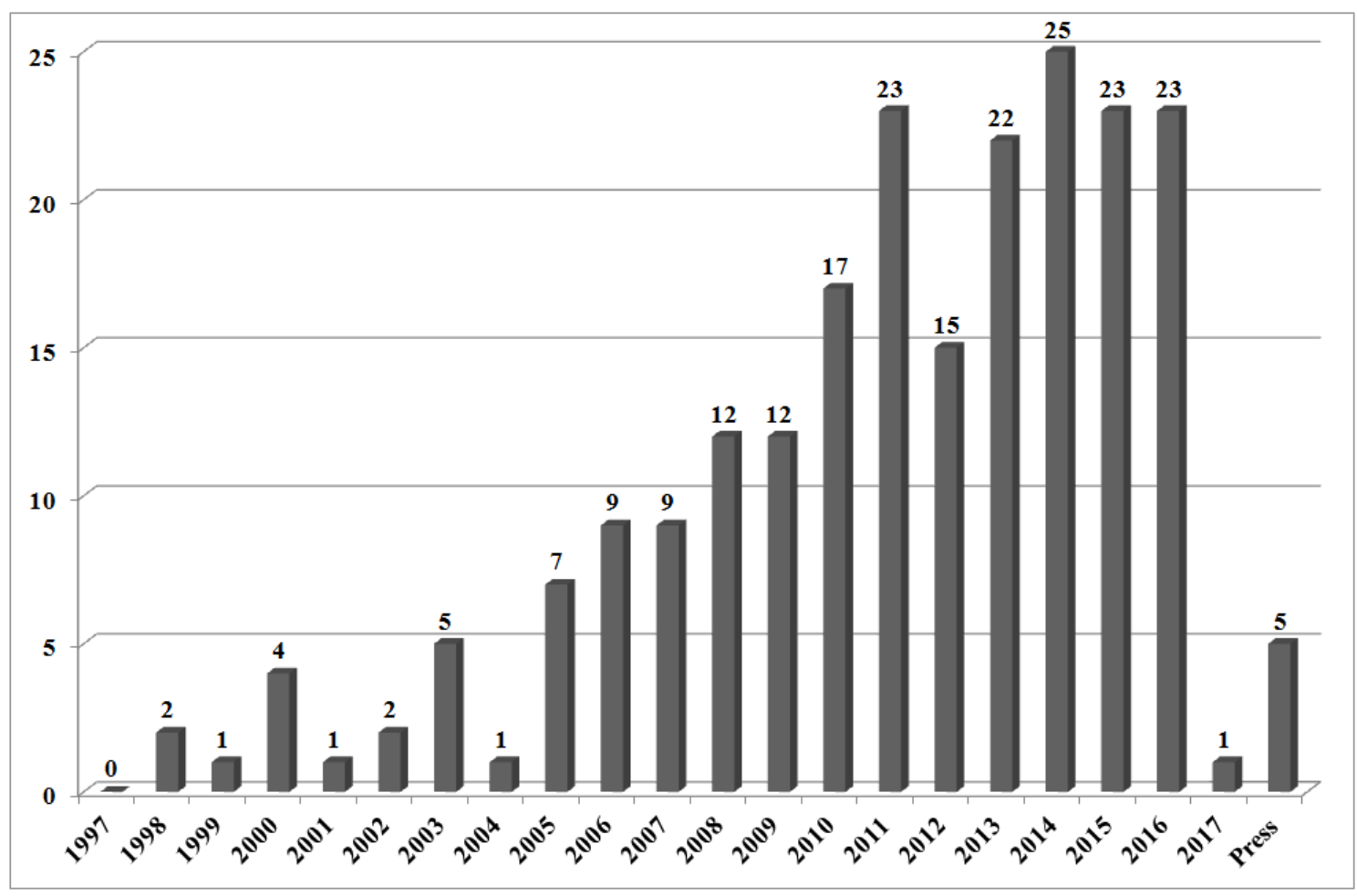

Fuente: Scopus y elaboración propia.

El profesor R. Law es Bachelor of Science (B.Sc.) in Computing Science and Economics (University of Lethbridge, Canadá), Master of Science (M.Sc.) in Computer Science (University of Regina, Canadá) y Doctor of Philosophy (Ph.D.) in Computer Science (University of Regina, Canadá). Por tanto, su perfil es eminentemente de ciencias, especializado en informática. Además, forma parte de múltiples consejos editores: Asia Pacific Journal of Tourism Research, 


\section{REFLEXIONES SOBRE EL TURISMO EN EL ÁMBITO ACADÉMICO ESPAÑOL}

Ramón Cardona, José

International Journal of Contemporary Hospitality Management, International Journal of Hospitality Management, Journal of Travel \& Tourism Marketing, Tourism Management, Journal of Hospitality \& Tourism Research, etc.

En comparación, los autores españoles con más artículos en revistas de turismo indexadas en Scopus están lejos de la producción de Rob Law: Juan Luis Nicolau (Universidad de Alicante) tiene 29 artículos, Joaquín Alegre (Universidad de las Islas Baleares) tiene 21 artículos, Carmelo J. León (Universidad de Las Palmas de Gran Canaria) tiene 14 artículos, Tomás López-Guzmán (Universidad de Córdoba) tiene 14 artículos, Juan Ignacio Pulido-Fernández (Universidad de Jaén) tiene 14 artículos, Jaume Rosselló (Universidad de las Islas Baleares) tiene 13 artículos, Jorge Pereira-Moliner (Universidad de Alicante) tiene 12 artículos y Javier Rey-Maquieira (Universidad de las Islas Baleares) tiene 10 artículos.

Al analizar las revistas iberoamericanas de turismo hay varios autores con bastantes publicaciones. José Álvarez García (Universidad de Extremadura, España) tiene 92 documentos en Google Académico y Maximiliano E. Korstanje (Universidad de Palermo, Argentina) llega a los 891 documentos en Google Académico, pero aún no ha sido posible revisar estas referencias para determinar cuántos artículos poseen en revistas de turismo iberoamericanas.

Si ha sido posible revisar en profundidad el currículum de José Manoel Gonçalves Gândara (Universidade Federal do Paraná, Brasil) y a 15 de septiembre de 2016 tenía 100 artículos de los que 91 eran en revistas iberoamericanas de turismo (Tabla 5).

Tabla 5: Artículos de J.M.G. Gândara en revistas iberoamericanas de turismo a 15 de septiembre de 2016.

\begin{tabular}{|c|c|c|c|}
\hline REVISTA & Latindex & Otras & TOTAL \\
\hline Anais Brasileiros de Estudos Turísticos & 2 & & 2 \\
\hline Caderno Virtual de Turismo (UFRJ) & 4 & & 4 \\
\hline Cuadernos de Turismo & 1 & & 1 \\
\hline
\end{tabular}




\section{REFLEXIONES SOBRE EL TURISMO EN EL ÁMBITO ACADÉMICO ESPAÑOL}

Ramón Cardona, José

\begin{tabular}{|c|c|c|c|}
\hline Cultur: Revista de Cultura e Turismo & 5 & & 5 \\
\hline El Periplo Sustentable & 4 & & 4 \\
\hline Estudios y Perspectivas en Turismo & 16 & & 16 \\
\hline International Journal of Safety and Security in Tour. / Hosp. & & 1 & 1 \\
\hline Investigaciones Turísticas & 3 & & 3 \\
\hline PASOS Revista de Turismo y Patrimonio Cultural & 1 & & 1 \\
\hline Revista Brasileira de Ecoturismo & 2 & & 2 \\
\hline Revista Brasileira de Pesquisa em Turismo & & 4 & 4 \\
\hline Revista de Analisis Turistico & 1 & & 1 \\
\hline Revista de Turismo Contemporâneo & & 1 & 1 \\
\hline Revista eletrônica de turismo cultural (USP) & & 3 & 3 \\
\hline Revista Hospitalidade & & 6 & 6 \\
\hline Revista Iberoamericana de Turismo & 1 & & 1 \\
\hline Revista Turismo \& Desenvolvimento & 2 & & 2 \\
\hline Revista Turismo em Análise & 5 & & 5 \\
\hline Revista Virtual de Direito do Turismo & & 1 & 1 \\
\hline Rosa dos Ventos & 5 & & 5 \\
\hline Tourism \& Management Studies & 3 & & 3 \\
\hline Tourism and Hospitality International Journal & 1 & & 1 \\
\hline Turismo 1 & & 1 & 1 \\
\hline Turismo e Sociedade & 6 & & 6 \\
\hline Turismo Tendencias e Debates & & 1 & 1 \\
\hline Turismo: Visão e Ação & 10 & & 10 \\
\hline Via@ - International Interdisciplinary Review of Tourism & & 1 & 1 \\
\hline TOTAL & 72 & 19 & 91 \\
\hline
\end{tabular}

Fuente: http://lattes.cnpq.br/2820622668034670 y elaboración propia.

Figura 6: Artículos de J. M. G. Gândara en revistas iberoamericanas de turismo. 


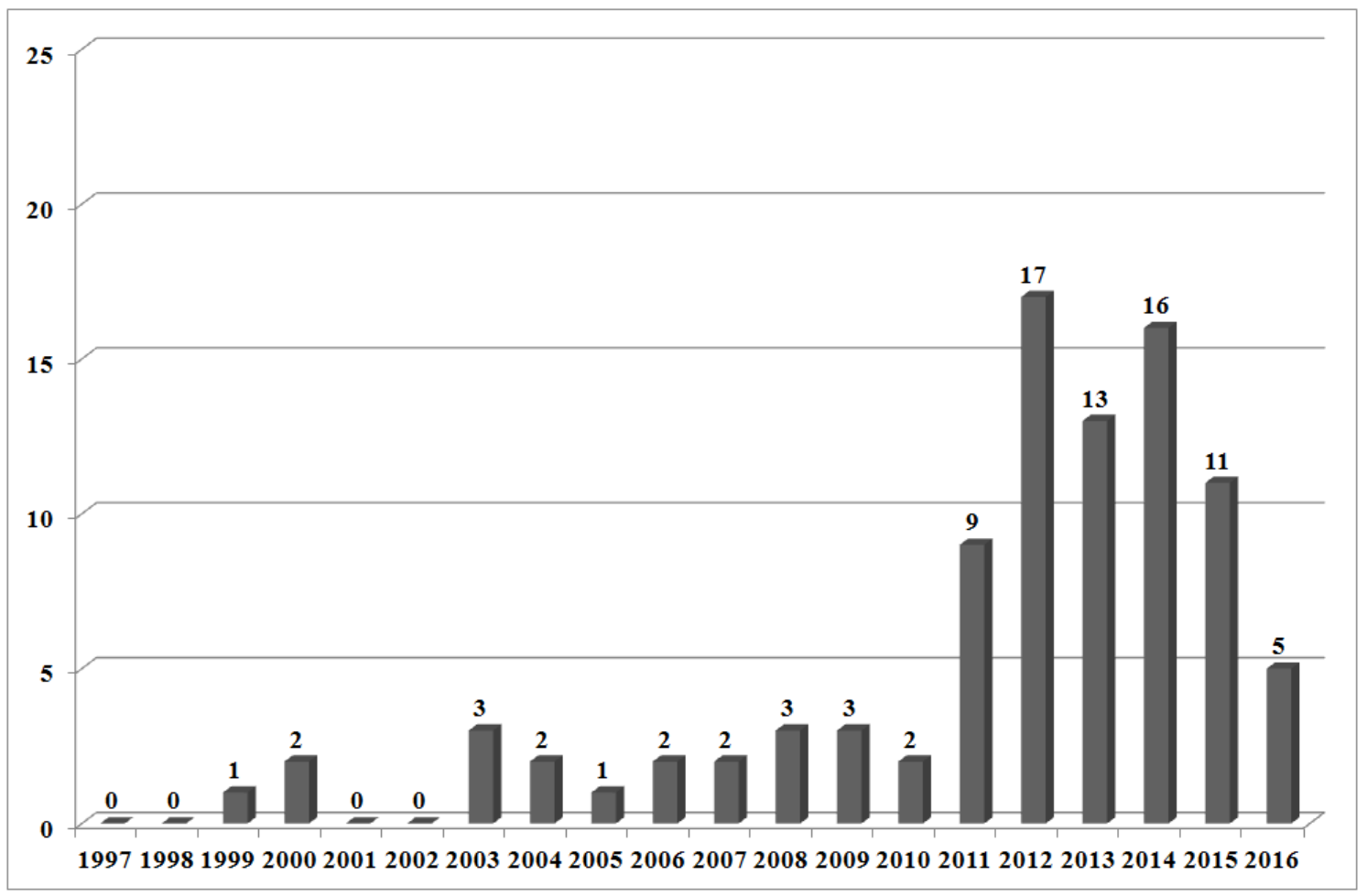

Fuente: http://lattes.cnpq.br/2820622668034670 y elaboración propia.

José Manoel Gonçalves Gândara es un caso claro de enfoque al turismo desde el primer momento, ya que es Graduado en Turismo (Universidade Federal do Paraná, Brasil), Máster en Gestión del turismo (Scuola Superiore Del Commercio Del Turismo i Dei Servizzi, Italia) y Doctor en Turismo y Desarrollo Sostenible (Universidad de Las Palmas de Gran Canaria, España), pero la mayoría de sus publicaciones son de los últimos seis años (Figura 6).

Tanto en el ámbito anglosajón como iberoamericano, los autores con mayor volumen de publicaciones se caracterizan por diversos elementos: dominio de las principales metodologías de análisis de datos en el área; una importante red de colaboraciones nacionales e internacionales; la concentración de las publicaciones en revistas del área, evitando dispersar artículos en cualquier tipo de publicación; y una fuerte dedicación a la investigación. En bastantes casos se trata de expertos en econometría, matemáticas o informática, ya que el análisis de datos es fundamental para el éxito en la publicación de resultados. 


\section{REFLEXIONES SOBRE EL TURISMO EN EL ÁMBITO ACADÉMICO ESPAÑOL}

Ramón Cardona, José

Finalmente hay que mencionar que en España no existe un área académica propiamente de turismo, implicando que las publicaciones en turismo son penalizadas en las evaluaciones de los investigadores al ser publicaciones "afines" y no del área. Las dos revistas de turismo con más artículos publicados en el periodo 2006-2015 de autoría española son Tourism Management y Tourism Economics. Tourism Management esta indexada en $\mathrm{SSCl}$ en las categorías de "Environmental Studies" (Q1), "Hospitality, Leisure, Sport \& Tourism" (Q1) y "Management" (Q1). Por ejemplo, para alguien de empresa un artículo en Tourism Management es evaluado como un JCR Q1 por estar en la categoría "Management", pero si sólo estuviera en "Hospitality, Leisure, Sport \& Tourism" sería evaluado como un JCR Q2 (penalización de un cuartil). Lo mismo pasa a los economistas con Tourism Economics, que esta indexada en $\mathrm{SSCl}$ en las categorías de "Economics" (Q4) y "Hospitality, Leisure, Sport \& Tourism" (Q4).

Tampoco se han creado departamentos de turismo y los investigadores en este campo se encuentran dispersos por diversos departamentos (Economía, Empresa, Geografía, Antropología, Sociología, Derecho, etc.) dificultando la colaboración entre los diferentes enfoques académicos. Además, existen pocas facultades de Turismo (normalmente estos estudios están englobados en otras facultades) y las existentes no han sido potenciadas lo suficiente. Por el contrario, en la mayoría de países con más publicaciones existe un área académica de turismo y hospitalidad, facultades o escuelas de turismo y departamentos de turismo y hospitalidad, permitiendo concentrar la docencia e investigación turística. Tampoco existe una penalización a los investigadores en turismo al existir un área para la cual las revistas en turismo son consideradas como propias.

\section{CONCLUSIONES Y PROPUESTAS DE ACTUACIÓN}


La situación de España en el ámbito académico no es tan buena como en el ámbito económico. España es el tercer país en llegadas de turistas internacionales, el segundo país en ingresos por turismo internacional (UNWTO, 2016) y el primero en competitividad (Gago \& García, 2016), pero es el séptimo en publicaciones en revistas académicas de turismo y hospitalidad (Figura 7). España poseía siete cadenas hoteleras entre las 100 primeras del mundo por número de habitaciones (Hotels, 2015): Meliá Hotels International (17ª ), NH Hotel

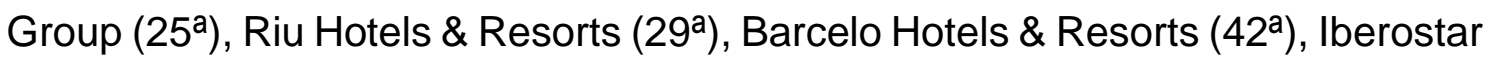

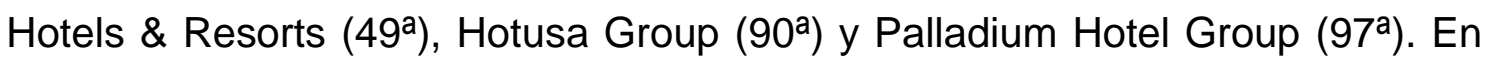
base a las revistas de turismo indexadas en Scopus, sólo tres universidades españolas estaban entre las 100 primeras por volumen de artículos publicados en el periodo 2006-2015: Universidad de las Islas Baleares (41를), Universidad de

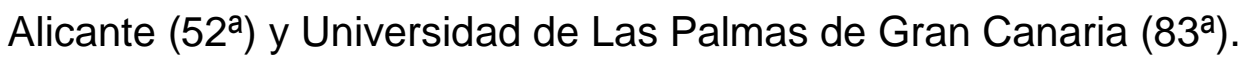

En base a los datos expuestos se pueden proponer algunas acciones para mejorar la investigación en turismo y hospitalidad que se realiza en España. Como medidas se propone:

- La creación de un área oficial de "Turismo y Hospitalidad", con todo lo que ello implica en listados de revistas del área, comisiones evaluadoras, etc. Además, sería recomendable crear dos perfiles oficiales para acercarse a la situación existente en otros países: "Turismo" y "Hospitalidad".

Figura 7: Más de 50 artículos en revistas de turismo (Scopus 2006-2015). 
REFLEXIONES SOBRE EL TURISMO EN EL ÁMBITO ACADÉMICO ESPAÑOL

Ramón Cardona, José

Estados Unidos

Australia

Reino Unido

China

Canadá

Taiw án

España

Corea del Sur

Nueva Zelanda

Turquía

Italia

Noruega

Malasia

Holand a

Francia

Grecia

Suecia

Portugal

Isr ael

Alemania

Sudáfrica

Austria

India

Suiza

Finlandia

Tailandia

Dinamarca

Jap ón

Singapur

E gip to

Irlanda

Croacia

Chipre

E. Á. U.

Eslovenia

Irán

Bélgica

Polonia

Brasil

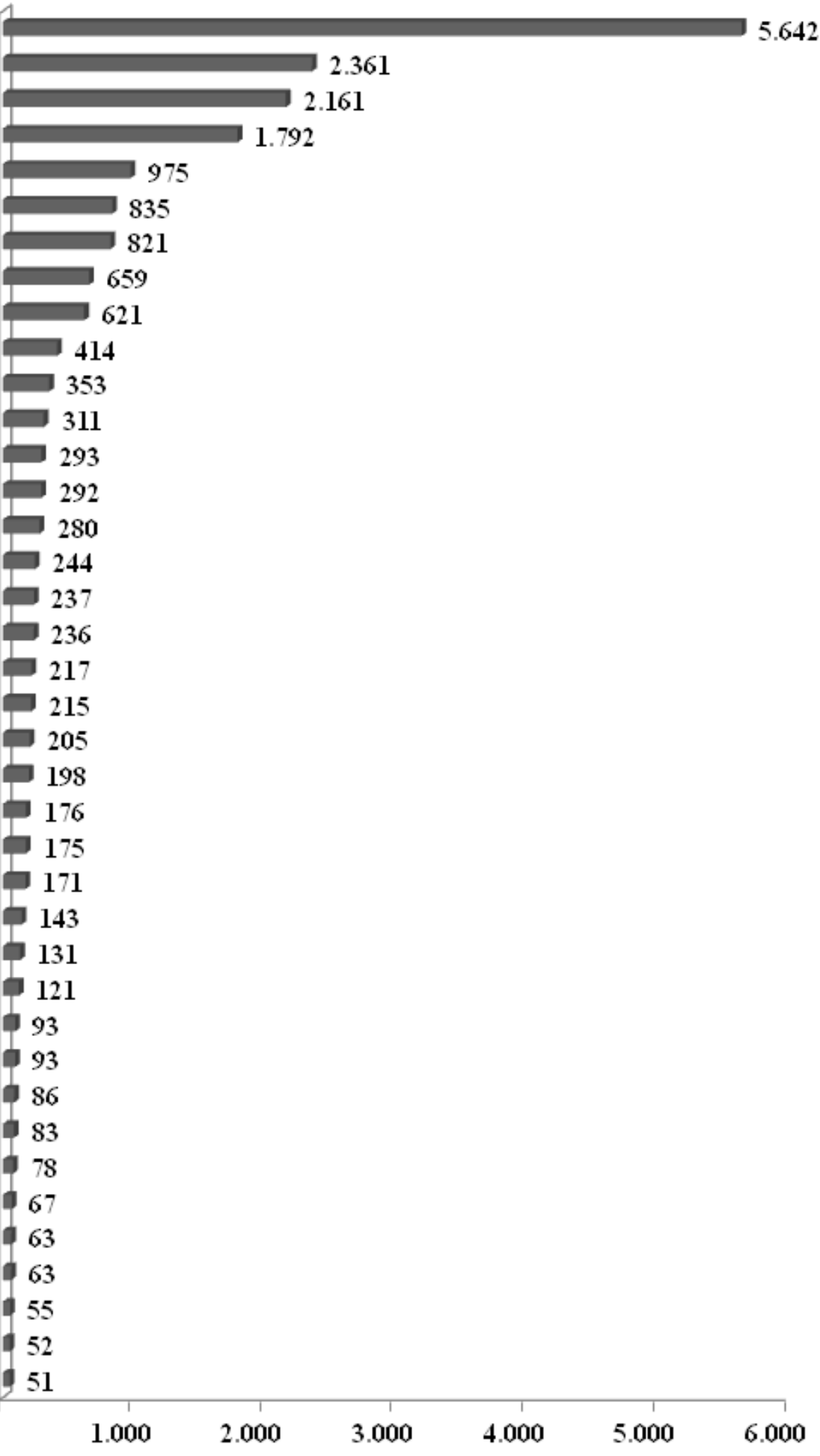

Fuente: Scopus y elaboración propia.

REDMARKA UIMA-Universidad de A Coruña - CIECID

Año X, Número 18, (2017), v I pp. 83-115

http://www.redmarka.net/ ISSN 1852-2300 
REFLEXIONES SOBRE EL TURISMO EN EL ÁMBITO ACADÉMICO ESPAÑOL

Ramón Cardona, José

- La recuperación del catálogo oficial de titulaciones dejando en el ámbito turístico las titulaciones propuestas en la Tabla 6. De esta forma cada título tendría un perfil profesional y académico claro y viable a largo plazo.

Tabla 6: Propuesta de titulaciones en Turismo y Hospitalidad.

\begin{tabular}{|c|c|c|c|c|c|c|}
\hline TítULO & 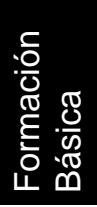 & 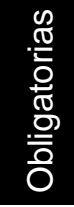 & 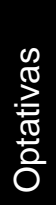 & 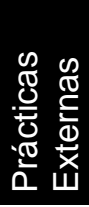 & 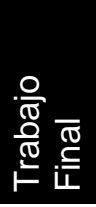 & TOTAL \\
\hline Grado en Turismo. & 60 & 120 & 36 & 12 & 12 & 240 \\
\hline Grado en Gestión Turística. & 60 & 120 & 36 & 18 & 6 & 240 \\
\hline Máster en Planificación del Turismo. & & 60 & 36 & 12 & 12 & 120 \\
\hline Máster en Dirección Hotelera. & & 42 & 6 & 30 & 12 & 90 \\
\hline Máster en Análisis Turístico. & & 36 & 6 & & 18 & 60 \\
\hline Doctorado en Turismo. & 15 & 10 & 30 & & 180 & 235 \\
\hline
\end{tabular}

Fuente: elaboración propia.

- La planificación de los centros y plazas realmente necesarios para evitar excesos de oferta. Ello evitaría la existencia de centros sin la plantilla adecuada y que los estudiantes obtuvieran una titulación poco demandada por el mercado laboral, siendo difícil trabajar en el área en que se ha estudiado.

- El aumento del nivel de exigencia en los estudios en turismo y hospitalidad para evitar que sigan siendo considerados estudios de segunda respecto a Economía y Administración de Empresas.

- La potenciación de las revistas españolas y su indexación internacional. Desgraciadamente, hasta el momento las revistas españolas son básicamente el resultado del trabajo desinteresado de los pocos profesores 


\section{REFLEXIONES SOBRE EL TURISMO EN EL ÁMBITO ACADÉMICO ESPAÑOL}

Ramón Cardona, José

que forman su equipo editorial. Un mayor apoyo desde las universidades y administraciones es necesario para mejorar su prestigio internacional.

- Fomentar la creación de departamentos o institutos de investigación que mejoren la colaboración entre los distintos enfoques investigadores. Mientras en el mundo anglosajón es muy habitual la existencia de departamentos de "Tourism and Hospitality" que concentran los investigadores de la universidad, en España aun no se ha creado ningún departamento de este tipo y los investigadores siguen dispersos en distintos departamentos y facultades.

- La potenciación de la publicación en revistas iberoamericanas y anglosajonas de turismo. Aunque hay excepciones, se debe fomentar una mayor presencia de los investigadores españoles en las revistas de turismo con el objetivo de que empiecen a aparecer profesores españoles en los listados internacionales. También se deben potenciar investigaciones más innovadoras y trabajos de ensayo, reflexión, revisión y aporte teórico. El peso de las publicaciones basadas en la mera comprobación de teorías previas mediante datos cuantitativos y análisis econométrico es excesivo en el conjunto de las publicaciones, en comparación con los países de referencia. Ello se plasma en la ausencia de aportes relevantes al cuerpo teórico de la materia.

En resumen, es necesaria una planificación nacional de la docencia e investigación copiando elementos de los mejores referentes internacionales y creando un sistema propio que resulte más eficiente e innovador que los existentes.

En futuras investigaciones resultaría de interés profundizar en la recopilación de información sobre revistas académicas (Whitelists y Blacklists), universidades e investigadores de referencia para aportar información útil a los estudiantes e investigadores que se incorporan al campo del turismo, además de ejemplos a seguir. 


\section{BIBLIOGRAFÍA}

Abril, M. (2015). Los estudios de Grado de Turismo. Asonancia o disonancia entre formación y profesión. El caso de los guías de turismo en la ciudad de Barcelona. Tourism and Hospitality International Journal, 4(2), 105-118.

Aguiló, E., \& Vich, G. A. (1996). La investigación en el ámbito de la política turística. Estudios Turísticos, 129, 23-36.

Albacete, C. A. \& Fuentes, M. M. (2010). Difusión de la investigación española sobre turismo en revistas internacionales. Revista de Análisis Turístico, 9(1), 1429.

Antón, S., López, F., Marchena, M. \& Vera, J. F. (1996). La investigación turística en España. Estudios Turísticos, 129, 165-208.

Ballantyne, R., Packer, J. \& Axelsen, M. (2009). Trends in tourism research. Annals of Tourism Research, 36(1), 149-152.

Bigné, J. E. (1996). Turismo y marketing en España: Análisis del estado de la cuestión y perspectivas de futuro. Estudios Turísticos, 129, 105-128.

Bote, V. (1996). La investigación en España sobre el turismo y desarrollo económico. Estudios Turísticos, 129, 9-22.

Bueno, E. J. (1996). La investigación sobre las empresas turísticas en España: el estado del arte. Estudios Turísticos, 129, 61-80.

Ceballos, C., Arias C., Ruiz, A., Sanz, C. \& Vázquez, I. (2009). La formación en turismo en España: Pasado, presente y futuro en el nuevo espacio europeo de educación superior. Cuadernos de Turismo, 25, 45-67.

Chang, C. L. \& McAleer, M. (2012). Citations and impact of ISI tourism and hospitality journals. Tourism Management Perspectives, 1, 2-8.

Cheng, C-K., Li, X. R., Petrick, J. F. \& O'Leary, J. T. (2011). An examination of tourism journal development. Tourism Management, 32(1), 53-61. 
Corral, J. A. (2013). Estudio Bibliométrico de las actas del Congreso de la Asociación Española de Expertos Científicos en Turismo (AECIT, 1994-2012). Revista de Análisis turístico, 16(2), 33-44.

Esteban, A. \& Reinares, E. M. (1996). La investigación de la demanda turística en España: recopilación y análisis. Estudios Turísticos, 129, 81-104.

Esteban, A. (2000). La investigación turística en la universidad española. Estudios Turísticos, 144-145, 17-46.

Ferreira, R. R., DeFranco, A. L. \& Rappole, C. L. (1994). Rating the hospitality journals. International Journal of Hospitality Management, 13(3), 209-218.

Frechtling, D. C. (2004). Assessment of tourism/hospitality journals' role in knowledge transfer: an exploratory study. Journal of Travel Research, 43(2), 100107.

Gago, P. \& García, E. (2016). ¿Cambios metodológicos o mejora relativa de España detrás de su posición global en competitividad turística 2015? Perspectivas. International Journal of Scientific Managment Tourism, 2(3), 99120.

Guevara, A., \& Caro, J. (2006). Situación, evolución y análisis de los estudios de turismo en Andalucía dentro del contexto de España. Malaga: Junta de Andalucia.

Hall, C. M. (2011). Publish and perish? Bibliometric analysis, journal ranking and the assessment of research quality in tourism. Tourism Management, 32(1), 1627.

Hotels (2015). 325 Hotels. Hotels, July/August, 23-40.

Jamal, T., Smith, B. \& Watson, E. (2008). Ranking, rating and scoring of tourism journals: Interdisciplinary challenges and innovations. Tourism Management, 29(1), 66-78. 
REFLEXIONES SOBRE EL TURISMO EN EL ÁMBITO ACADÉMICO ESPAÑOL

Ramón Cardona, José

Jogaratnam, G.,Chon, K., McCleary, K., Mena, M. \& Yoo, J. (2005). An analysis of institutional contributors to three major academic tourism journals: 1992-2001. Tourism Management, 26(5), 641-648.

Kim, Y., Savage, K. S., Howey, R. M. \& Van Hoof, H. B. (2009). Academic foundations for hospitality and tourism research: a reexamination of citations. Tourism Management, 30(5), 752-758.

Law, R., Leung, R. \& Buhalis, D. (2010). An analysis of academic leadership in hospitality and tourism journals. Journal of Hospitality \& Tourism Research, 34(4), 455-477.

$\mathrm{Li}, \mathrm{J} . \& \mathrm{Xu}, \mathrm{Y}$. (2015). Author analyses of tourism research in the past thirty years-Based on ATR, JTR and TM. Tourism Management Perspectives, 13, 16.

McKercher, B. (2005). A case for ranking tourism journals. Tourism Management, 26(5), 649-651.

McKercher, B. (2008). A citation analysis of tourism scholars. Tourism Management, 29(6), 1226-1232.

McKercher, B., Law, R. \& Lam, T. (2006). Rating tourism and hospitality journals. Tourism Management, 27(6), 1235-1252.

Moreno, S. \& Picazo, P. (2012). Difusión de la investigación científica en revistas de turismo realizada por instituciones españolas. Revista de análisis turístico, 14(2), 33-52.

Park, K., Phillips, W. J., Canter, D. D. \& Abbott, J. (2011). Hospitality and tourism research rankings by author, university, and country using six major journals: The first decade of the new millennium. Journal of Hospitality \& Tourism Research, 35(3), 381-416. 


\section{REFLEXIONES SOBRE EL TURISMO EN EL ÁMBITO ACADÉMICO ESPAÑOL}

Ramón Cardona, José

Pechlaner, H., Zehrer, A., Matzler, K. \& Abfalter, D. (2004). A ranking of international tourism and hospitality journals. Journal of Travel Research, 42(4), 328-332.

Picazo, P. \& Moreno, S. (2012). Difusión de la investigación científica de turismo en Chile y Argentina. Gestión Turística, 18, 9-45.

Picazo, P. \& Moreno, S. (2013a). Difusión de la investigación científica en turismo: El caso de México. El Periplo Sustentable, 24, 7-40.

Picazo, P. \& Moreno, S. (2013b). Difusión de la investigación científica iberoamericana en turismo. Estudios y Perspectivas en Turismo, 22(5), 828-853.

Picazo, P., Moreno, S. \& León, C. J. (2012). Difusión de la investigación científica de turismo en Brasil. CULTUR-Revista de Cultura e Turismo, 6(4), 4-36.

Ryan, C. (2005). The ranking and rating of academics and journals in tourism research. Tourism Management, 26(5), 657-662.

Severt, D. E., Tesone, D. V., Bottorff, T. J. \& Carpenter, M. L. (2009). A world ranking of the top 100 hospitality and tourism programs. Journal of Hospitality \& Tourism Research, 33(4), 451-470.

Sheldon, P. J. (1991). An authorship analysis of tourism research. Annals of Tourism Research, 18(3), 473-484.

Svensson, G., Svaeri, S. \& Einarsen, K. (2009). "Empirical characteristics" of scholarly journals in hospitality and tourism research: an assessment. International Journal of Hospitality Management, 28(3), 479-483.

Tribunal de Cuentas (2015). Informe de Fiscalización de las Universidades Públicas, Ejercicio 2012. Madrid: Tribunal de Cuentas.

UNWTO (2016). Tourism Highlights: 2016 Edition. Madrid: UNWTO.

Vargas, A. (2011a). ¿Los principales destinos son también las principales potencias en la investigación en turismo? Estudios Turísticos, 188, 91-111. 
REFLEXIONES SOBRE EL TURISMO EN EL ÁMBITO ACADÉMICO ESPAÑOL

Ramón Cardona, José

Vargas, A. (2011b). Tourism Research in Spain: The state of the art. Enlightening Tourism: A Pathmaking Journal, 1(1), 93-110.

Vera, J. F. \& Ivars, J. A. (2001). La formación y la investigación turística en España: una visión de síntesis. Papers de Turisme, 29, 6-27.

Zhao, W. \& Ritchie, J. R. B. (2007). An investigation of academic leadership in tourism research: 1985-2004. Tourism Management, 28(2), 476-490.

\section{Páginas Web:}

https://scholar.google.es/

http://www.ine.es/

http://ip-science.thomsonreuters.com/mil/

http://www.mecd.gob.es/

https://www.educacion.gob.es/ruct/home

http://hotelschool.shtm.polyu.edu.hk/eng/index.jsp

https://www.scopus.com/home.uri

http://www.latindex.unam.mx/latindex/inicio

http://www.udg.edu/

http://www.uib.es/ 